\title{
Delivery of written assessment e-feedback to year abroad Mandarin learners
}

\author{
Zhiqiong Chen
}

\begin{abstract}
Feedback plays an essential role in student learning. It is relatively easy to provide learners with feedback in a face-to-face teaching setting. When they are at a distance, it is necessary to reconsider the delivery of feedback to meet students' academic and emotional needs. In this small-scale study, targeted learners studied Mandarin at equivalent CEFR B1 level and they received screencast feedback on writing assessments while on year abroad and the feedback was focused on detailed syntactical and lexical corrections. The study aims to understand student and teacher perceptions of this kind of screencast feedback and student uptake. Apart from the positive view shared by many existing studies that video feedback enhanced the student feedback experience, the findings revealed that students desire feedback on languages. However, the existence of such feedback did not necessarily lead to student active feedback engagement. It also reveals that despite recognizing the pedagogical value of this practice, teachers were concerned about the process being time-consuming. Based on these findings, implications of this study are addressed which could be helpful to teachers in a wider context when providing feedback. Future research is also suggested.
\end{abstract}

Key words: video feedback, corrective feedback, feedback update

\section{Introduction:}

Feedback plays an essential role in student learning. While working or studying abroad, students do not normally have formal contact with their subject teachers at the home university, and their assignment feedback becomes the only connection between them and the teacher. In the case where students do not choose to study their subject abroad, such feedback could be the only formal feedback they get during their year abroad (YA) period and becomes an important academic progress or competence retention indication for them to continue the subject after returning from YA. Due to very limited communication between those students and the teachers, to engage students with feedback, clear and useable feedback becomes even more important than in a normal classroom teaching setting, hence the feedback delivery needs to be reconsidered in relation to the tool and the content.

\section{Benefits of video feedback to students}

In higher education, across different disciplines, using digital technology, such as screencast videos to give students feedback is not something new. The qualitative synthesis review of video feedback in HE gathered research across different disciplines and the evidence suggests that "video feedback is a promising alternative 
to the traditional written feedback" (Mahoney et al., 2019, p. 170). In their paper, video feedback includes screencast feedback, talking head video feedback and the combination of both. In screencast videos, students will see what the teacher has captured on the screen which could be documents, videos and websites and at the same time, hear the teacher's audio narration over the on-screen images. They can also follow teacher's mouse movement and typing if he/she did so. With talking head video feedback, students only see the teacher's physical appearance while listening to his/her audio narration. From the student's perspective (Mahoney et al., 2019) screencast feedback has improved feedback clarity and is easy to understand. It is very often personal and individualised, so students felt as if they were being valued as individuals and there was a connection with the teacher. They tend to watch video feedback multiple times or spend more time reviewing video feedback than that in written form. Being able to hear the teacher's tone of voice in videos can also help students to understand better the markers' expectation and to be motivated. In an online writing course, when students have little or no face-to-face contact with teachers, Thompson and Lee (2012) found the audio component in screencast feedback not only enabled the teacher to give indepth explanations, but also created a more personal mentoring connection with students. The affection benefit delivered through verbal comments is also evident in the study of Ice et al. (2007) in which learners reported that audio feedback "produced a more comfortable, less formal learning environment" and they felt increased involvement in the course and being cared for.

In second language education settings, similar advantages of screencast feedback have been reported (Harper et al., 2018; Alharbi, 2017) and students had very positive views on screencast feedback (Séror, 2012). When giving EFL students both combined oral and written feedback to their writing using screencast technology, Alvira (2016) found that student autonomy has increased due to high levels of motivation produced from such feedback. As an additional benefit, screencast feedback allows students to hear the teacher speaking in the target language, which increases their exposure to the spoken language (Harper et al., 2018). Thompson and Lee (2012) also pointed out the potential language benefit when teaching multilingual speakers' writing: teachers can model Standard English or other commonly spoken forms when reading sentences aloud. In fact, in a college entry level writing class, being able to hear the language is also mentioned as an additional benefit (Vincelette \& Bostic 2013). One thing research hardly mentions is that some screencast websites provide video view numbers which could be used to indicate whether students have watched given feedback video or not. All these advantages suggest that screencast is a good vehicle for delivering feedback to language learners when they are studying or working abroad. 


\section{Second language writing and written corrective feedback}

There are two general dimensions in second language writing (Rosa, 2011): learning-to-write, in which the second language users learn to express themselves in writing, and writing-to-learn. The former focuses on developing good writing and writer development while the latter has two focuses: writing-to-learn content which does not only develop learners' writing skills, but content knowledge; and writing-to-learn language which is to support language development. Importantly, Ortega (2011) concludes that these three perspectives are closely related in second language writing. From whichever dimension second language writing is viewed, feedback plays an important role in the language learning process.

In second language acquisition, written corrective feedback WCF is also known as 'grammar correction' or 'error correction' and is 'a conventional tool second language teachers use to help their students improve accuracy in writing' (Mao \& Lee, 2020, p. 1). There have been many discussions on the effectiveness of WCF in the improvement of second language writing accuracy. However, this is beyond the scope of this paper. Other discussions are on strategies in delivering WCF: indirect vs direct (whether there is provision of correct forms of marked errors) and explicit vs implicit (whether errors are marked with codes or metalinguistic explanation or unlabeled). There is no universal strategy to ensure the efficacy of WFC as it can be influenced by individual and contextual factors. Furthermore, other research focuses on the scope of WFC. To organize various confusing categories used in WCF research, Mao and Lee (2020) used the terms comprehensive WCF and focused WCF, with the former referring to feedback on all errors and the latter, on a limited range of error types. Lee (2019) argued that less written corrective feedback is better, based on analyses of the problems of comprehensive WCF and the benefits of focused WCF. However, the scope of WCF remains an unresolved issue in second language learning (Mao \& Lee, 2020).

When marking student writing using video feedback, some studies (Orlando 2016; Ice, et al., 2010; Vincelette \& Bostic2013) showed that teachers tended to discuss less micro-level, or low-level writing issues in video, instead substantive or global feedback were delivered. Micro-level issues refer to word choice/phrasing; missing words and pieces; grammar/punctuation; spelling/typos, etc. (Stern \& Solomon, 2006). It is worth noting that these studies were not in the field of language learning. In an EFL study (Alvira 2016) the feedback was focused on content over form, so students can focus on the communicative purpose of writing (McGarrell \& Verbeen, 2007 in Alvira 2016). Unexpectedly, the study finding shows that the majority of student improvement is in the grammatical aspect. Harper et. al (2012) report that when providing screencast feedback to distance language learners, tutors prioritised their individualised feedback based on the 
student's needs but considered addressing grammatical accuracy as the main need for using such technology.

\section{Aim of the study}

In the context of YA Mandarin students, it is challenging to provide comprehensible feedback on language assignments, as not all of them were in Mandarin speaking countries and/or taking formal Mandarin classes, and thus lacked resources to clarify unclear language issues if they did not proactively contact teachers. On the other hand, teachers were frustrated as it was hard to know whether students were engaged with the feedback they provided. The overall aims of this project were to investigate whether personalized screencast feedback which focused on micro-level writing issues on assignment writing could better meet YA Mandarin learners' needs. If this is the case, then what is the possibility for language teachers to adapt such a method, not only for this group of students but potentially in a wider context?

Specially, the study tried to understand:

1. Whether the screencast video, in comparison with written feedback only, helps to engage YA students.

2. Whether students value the video contents which is focused on micro-level issues.

3. Language teachers' perceptions of screencast feedback, in comparison with the traditional written feedback, either in YA student setting or not.

\section{Methods}

\section{Research setting}

In this study, the feedback recipients are a group of learners who were taking Chinese as part of their degree study and were having their year abroad. The time when they were YA, their Chinese proficiency level was equivalent to CEFR B1. During their year abroad, not all of them chose to go to China to advance their language skills. Those who went only stayed for up to 6 months maximum. For those who did not go to China, they might or might not access formal Mandarin classes. All of them had language writing assignments twice a year as required academic work where they had to use handwriting in order to practice Chinese characters. Students submitted the scanned work, normally as a PDF file or pictures via the institutional online platform. Their writing was assessed with set criteria which they were familiar with, though the marks did not count toward their degree. 
To each student's work, apart from providing an actual mark based on the marking criteria, summary comments focused on the macro-level, such as content, ideas and the structure of the writing, and forward feeding on how to improve their work was provided in writing. In addition, a feedback video was created for each piece of writing, unless it was not necessary due to the high quality of work. First, corrections on language errors or indications of errors were annotated on students' scripts. Then the free online screencast tool, Screencast-O-Matic (S-OM) (https://screencast-o-matic.com/home) was used to capture the marked script on screen accompanied with the marker's audio narration. In videos, student's writing was read out sentence-by-sentence. Depending on errors, sometimes the marker asked questions to encourage students to self-correct before providing explicit feedback, which was followed by a detailed explanation. In addition, praise on language use was given verbally whenever possible.

Normally the videos were about 5-10 minutes long, depending on the length and number of errors in each writing. To distribute feedback videos, video links were pasted at the end of the summary comments and then uploaded to the online submission platform alongside the marked scripts and the actual mark.

\section{Data collection}

This study invited nine out of eleven students (two years' cohort) who were studying Chinese as part of their degree and went abroad, either spending time in China or not. Seven students responded and participated in this study. At the time the study took place there was a very small number of such students each year in the department, which limited the number of participants. All seven students were interviewed either face to face, online via video conference or through phone call, as some students were still abroad when the study was conducted. The interview questions were focused on their experience of using video feedback and how they value the contents in feedback videos. Students were also asked about the advantages and disadvantages of receiving feedback in video format.

Four staff members were invited, among whom three were markers of YA academic work of other languages. One Mandarin teacher who was not a marker of YA academic work, but had experience of giving video feedback, was also invited. Two teachers had face-to-face interviews and two filled in online questionnaires depending on their availabilities. Before taking the interview or online questionnaires, each staff were given one randomly selected feedback video to watch, so they had an idea how feedback was delivered. Both the interview questions and the questionnaire asked staff for their views on the scope of feedback language teachers should provide to students and the potential advantages or disadvantages of video feedback either based on their understanding of the sample feedback video or their own experience. 
The third part of the data was online records provided by the Screencast-0-Matic website. It automatically records the number of views of each video created and uploaded on its website.

\section{Results}

\section{Student views}

\section{Uptake of video feedback}

After receiving the feedback package, the general order that students read each part were: the actual mark first, then the summary comment which was followed by the marked script and the screencast feedback. Two students claimed that they did not watch the screencast feedback straight away but waited till they had time which could be a few days later. One did not watch the screencast feedback until she started writing assignments in the following term which could be a couple of months after receiving the feedback package.

All the students pointed out that the first thing they checked when receiving the feedback packages was the actual mark.

\footnotetext{
"Mark is very important to know where you are in [university]... I think we look at the mark straight way and (then) look at the feedback. I did that with all my essays and things, just for that kind of relief to be OK, I did alright, then you get critic and feedback..." (S1).

"Obviously that is the first thing I looked at. The mark is a good indicator of course where I am, in comparison with the second year." (S7)

"The marks are important, as long as it is a decent mark, then I am happy... If it is the end of the year mark, I will be obviously very concerned about the mark... I am naturally nervous about the mark. Mark is the first thing you see on the website. Maybe the website creates the feeling that the mark is very important". (S4)
}

However, all the students consider feedback on the language was the most important, including corrections and explanations.

"When I received the feed back, what I am most interested is what to improve next time, so clear correction is very important. Then I can use that as the template. I can improve next time. From my previous experience of learning languages, the most important thing is practicing. It's almost like performance when you speak a language, I think, which comes from memorizing phrases, structures... So if I have a clear corrections telling me what I have to say next time, I can remember that and then use it again." (S4)

"Knowing when you made mistakes and how you've been corrected is more important, because you can apply more directly, ...For me learning YA, there is no face to face interact in class, so it is important. It will be more important for my independent learning." (S7)

"Clear explanation and clear explanations are the most important. With indication of what type of mistakes, I am still not 100\% sure about the correction, so still prefer clear correction... Simple mistakes [I] 
can self-correct, but more complicated, still need to ask the teacher questions. Indication is good for simple mistakes, such as missing radical in characters, I can look it up... for complex sentences I probably will ask you again." (S5)

Not all the students tried self-correcting following the error indications, although they agreed it was good practice to "remember things more". In general, students were not confident enough with their own corrections. They might figure out the solution to grammatical issues if it had been taught but struggled with lexical errors and unlearnt grammar. Those who did self-correct also counted on the feedback video's backing for confirmation. With detailed explanations they could know "why this should be the correction, why needs such a change" (S2).

Most of the students felt it was necessary to know all the errors so they could avoid making the same mistakes again, thus they wanted the feedback on language to be as detailed as possible. They were aware of their Chinese proficiency level and accepted the fact that there might be many errors. Regarding examining through the whole passage sentence by sentence in feedback video, students thought:

\footnotetext{
"Even it is not a serious mistake, it is a very honest opinion from a Chinese speaker, it is important to know, especially for Chinese. I know with Chinese, I will make lots of mistakes, so I won't think it too hard, just accept my mistakes. I need to improve. I need to motivate me. I need to be very honest to myself about my level. So sentence by sentence doesn't bother me necessarily." (S4)

"Ideally, [I] like sentence by sentence. If there are lots of mistakes, might be off-putting if teacher marks all the mistakes, at first glance. However, it is useful to go back to have a thorough correction. Otherwise, I not necessarily pick it up." (S2)

"Go through sentence by sentence for language corrections if possible. You also point out good sentences, so you give fair feedback... don't find it demotivating." (S7)

"II] rather have each mistake to be pointed out, so won't make the mistake again. But it will be a lot for teacher to do. In this case, maybe big errors are more important... I am perfectionist, so would like to have all the mistakes picked up, as detailed as possible." (S1)
}

There was one student who was concerned that too much error correction might be overwhelming but did not state if it was her feeling.

None of the participants mentioned any problem when accessing videos. They all took control when watching videos, using the pause, rewind and reply buttons. Only one student mentioned that she played forward to skip some parts. Some students took notes on their original work whilst watching the videos, for example, making all the corrections following the video explanations. Some did not, because they thought they could access the videos anytime when needed, so it was not necessary to note down everything. 


\section{Advantages and disadvantages of video feedback}

In comparison with written feedback, students reported that in videos, explanations were more thorough and detailed.

\footnotetext{
"For me, having someone guide me through it (the feedback) is better. I feel that sometimes people do not put all the details in the written feedback, because you can write pages. Sometimes, they like to hold back a little bit." (S7)

"Work in the past can be confusing with lots of abbreviations and categories of [language] mistakes." (S4)

"They (markers of a different language) correct it with pen on a piece of paper, but you can't really know the explanation, you would have more doubts." (S5)
}

Students found it especially convenient to have video feedback when the explanation could not be given right next to the mistakes in their scripts and understood that "it will be too much to use written feedback for all the corrections" (S7). They thought the combination of the corrected script and the video worked very well. Some students found it easier to watch a video than reading a long-written feedback as it waseasier to understand what the problem was. Students who had no problem reading long written feedback also felt it was better to see the feedback visually, especially if there were a lot to improve, because "when you read it, you might not take everything in, but when you see it, it would be better" (S5).

Students used the word 'quite spontaneous', 'more instantaneous' and 'very honest' to describe verbal feedback. When listening to the verbal feedback, they felt like "having someone sit next to you" (S6), and "chatting with someone" (S2), thus felt "very personal, interactive" (S3). Therefore, they "feel a bit more connected during YA with video feedback" (S1). "Some other work you even don't know the marker. Make it feel that you are not cared about" (S2). One student also pointed out that "if students conscious about the mark, video feedback will make them feel a bit closer to the marker" (S4). In addition, students valued marker's reading in the target language. They pointed out that Chinese was a very challenging language because it was a tonal language, and the written form did not indicate the pronunciation. The combination of hearing it and seeing it made it easier to remember it. In addition, it "helps with intonation, more exposure to the target language" (S7). When being asked whether they would like to see the marker appearing in the video, all the students responded not necessarily, because it will not add any "attractions" but could be "a little distraction", as they would like to concentrate on the feedback itself.

While most of the students praised the advantages of screencast feedback, one pointed out that screencast feedback might not be the student's personal preference, although the person did not say explicitly whether it was her case or not. Two other students mentioned that when the video was long, about 10 minutes, 
they could lose attention. There is also a possibility that students may not be able to catch all the verbal corrections in the target language if they were not in written form and then get lost in translation.

\section{Teacher review}

It is worth noting that three teachers had experience of using screencast either for creating teaching materials or providing feedback on students' homework writing in a face-to-face teaching setting. None of them has provided screencast feedback to YA students on their assessed work. One common frustration was that teachers did not know whether YA students read the written feedback they provided or not. They noticed that some students did not even download feedback files from the submission website. When students downloaded them, there was no way to verify whether they read them or not, as they did not email back to ask questions. One teacher proposed that a follow-up email to students could help but admitted that she had not done so. The teacher who had used various screencast tools to give students feedback, checked verbally with students in class whether they watched it or not, but did not monitor students' views. After recording feedback on screen, this teacher downloaded it as a MP4 file which was then sent to students via email. For long videos which could not be sent via email, for example longer than 10 minutes, the teacher put them on the personal Google drive and then shared the links with students or cut a long video into shorter parts then sent them via email. Therefore, it was impossible to find out how many times students viewed the videos. Since the feedback was sent via email, most students tended to reply saying thanks which might or might not suggest that they had watched the videos.

All teachers agreed that screencast feedback was more engaging, personalised and convincing. Feedback videos "would make students curious to hear what was going to be said" and "with the tutor's familiar voice, even if a lot of comments are negative comments (i.e., correcting mistakes), it sounds still encouraging" (T3). From the teacher's point of view, explaining language orally is a more efficient way, as markers can "explain in an easy way, in a faster way and possibly even in a more detailed way" (T4). Because teachers can illustrate, "in terms of explanation, it works well" and potentially, it is "easier to explain what they (student) should do to improve and add specific resources" in videos (T4). Screencast feedback "might be helpful in avoiding lengthy emails or documents to explain the point. The visual aspect may work very well with the majority of students" (T1).

When giving feedback in written form, teachers comment on both the macro-level and micro-level and 'do as much as they can'. 
"I believe feedback should include all the necessary aspects. A summary of these should be provided and explained to students so they have a pattern of errors that they can be made aware of." (T1)

"As much as possible... I gave them quite detailed feedback, I think at this level, you should give feedback in terms of structure, macro structure, details, ... explaining what you have been doing better, worse etc... so, I do give quite specific feedback, ... vocabulary, syntax, general structure etc. everything. I correct the mistakes and comment on the one that seem to be the most striking, then I write general comments, then add per category each, say how many mistakes you made each... I counted, so students understand which area they need to work more on... It is not to discourage them. I try to make the text encouraging, but I try to be very specific... I try to categorize [errors] and add comments for each category". (T4)

The teacher who has been using screencast for feedback, "picked up each mistake", only "gave corrections in script" and then "explain everything in videos". For advanced level students, in addition to language errors, structures and ideas were commented heavily on in videos.

In regard to whether screencast feedback could help with building a relationship between teachers and students, the teacher who never used video feedback believed it was "obvious" in a YA setting where there was lack of interactivity between the two parties. The teacher who was an experienced video feedback user firmly agreed that by listening to the teacher's voice, students felt more connected with the teacher even in a classroom setting. In addition, teachers pointed out that being able to read out students' work in the target language might be useful for students.

One common concern from teachers was the time required to produce screencast feedback. Apart from creating videos, students' work has to be corrected before producing such videos, and it would be difficult to edit once the video is recorded. Three teachers who had used screencast either for feedback provision or other purpose, believed that producing feedback video required more time than simply giving feedback in written form. The other teacher was uncertain whether extra scanning and uploading files would take more time or giving feedback verbally would save time. Based on this concern, two teachers suggested screencast would be better used for group feedback. The other two would like to try it in a small group, but one felt it quite "daunting" to use such technology. Another concern mentioned by two teachers was that weaker students might not be able to understand verbal corrections in the target language when corrections were not provided in the script.

\section{Website record of number of views}

As mentioned earlier, the free S-O-M website provides basic analytical figures: the record of video view numbers. Although such data cannot indicate how students watched the videos, for example whether they watched the whole video or not 
and which parts of the video they have watched, at least it shows how many times they have played the video.

For the two years' cohort, 11 YA students received 48 feedback videos in total, but the online figure shows only $54 \%$ of videos were played.

Among four students who did not participate in this study, only one watched all the videos that were created for her and the rest watched none. Four of the seven students who joined in this study, did not play all their own videos. However, two of them played some of their videos 2-3 times. On average, each video was played 1.7 times. Below is the table of student view numbers on each video.

Tab. 1: Student view numbers on each video

\begin{tabular}{|c|c|c|c|c|c|c|c|c|}
\hline \multirow{2}{*}{ Student } & \multicolumn{3}{|c|}{ Term 1 assignment } & & \multicolumn{3}{c|}{ Term 2 assignment } & \\
\cline { 2 - 9 } & Video 1 & Video 2 & Video 3 & Video 4 & Video 1 & Video 2 & Video 3 & Video 4 \\
\hline A. & - & - & - & - & 1 & 1 & 3 & - \\
\hline B. & - & - & - & - & 3 & 4 & - & - \\
\hline C. & - & - & - & - & 1 & 0 & 0 & - \\
\hline D. & - & - & - & - & 2 & 2 & 3 & 3 \\
\hline E. & - & - & - & - & 0 & - & - & - \\
\hline F. & 1 & 1 & 0 & - & 1 & 1 & 1 & - \\
\hline G. & 2 & 2 & 3 & - & 1 & 1 & 0 & - \\
\hline H. & 1 & 1 & 1 & - & 0 & 0 & 0 & - \\
\hline I. & 2 & 1 & 1 & - & 0 & 0 & - & - \\
\hline J. & 0 & 0 & 0 & 0 & 0 & 0 & 0 & - \\
\hline K. & - & - & - & - & 0 & 0 & 0 & - \\
\hline
\end{tabular}

Note: One year's cohort, students A to E only received screencast feedback on their term two assignment when the marker started using this delivery mode. The rest, apart from student $\mathrm{K}$, all received screencast feedback twice for both terms' assignments. Student K's term one writings were unexpectedly good; thus, video feedback was not needed.

\section{Discussions}

\section{Students prefer Screencast feedback}

Based on interview data, screencast feedback is easier to receive. First, the nature of the video, illustrating student's work together with the teacher's visual markup and verbal explanations, makes it more convenient for students to follow the flow. Because of its spontaneity, video feedback is believed to be honest, which indicates a level of student trust. In this study, students felt the video feedback was encouraging, even when there were many corrections, and it could be the fact that in videos the marker could give more praise verbally without worrying about the 
mark-up being overloaded as in the written form. Even when the audio feedback is practically a one-way communication, students feel the sense of communication. Unlike written feedback, the video provides teachers with an opportunity to apply different types of corrective feedback that are normally used in the classroom, for instance providing the correct form immediately after indicating errors, or giving a metalinguistic clue with a pause to allow students' self-corrections before giving the answer or explanation. Depending on how students watch it, when they pause the video and take the opportunity to reflect and take notes, there is an element of interaction and student involvement.

Apart from being able to stimulate students' involvement, students stated that verbal explanations also tended to be more personalized, as they were focused on each individual piece and the affection conveyed by the tone of spoken languages give students a sense of rapport. Building relationships between teachers and students plays an equally important role as the right feedback message promotes proactive recipience of feedback (Winstone et al., 2017). Indeed, the affective impact of screencast feedback is particularly beneficial to students who are at distance (Harper's et al., 2012). Thomas et al. (2017 in Carless \& Winston, 2020) stated that the relationship building is partially because the video feedback enables the marker's social presence, although in this study the marker was not physically present in the videos. In fact, some students considered the marker's physical presence as unnecessary or perhaps having a negative impact.

In this study, students recognize teachers' reading in the target language is helpful in both learning the language and practicing the pronunciation. Since there is no correlation between the pronunciation and the written form in Chinese, the input combining both the written forms and the sound make the learning easier, especially when students have no opportunities to practice the language while at YA. Such benefit might be more significant to learners of Chinese. All the positive aspects above of video feedback contribute to solving the issue that students did not feel cared about, both academically and emotionally.

\section{Written corrective feedback is necessary}

Since learning to write, writing-to-learn language and content are interweaved, in this study the link to feedback videos was given at the end of the summary feedback, aiming to avoid students skipping macro-level feedback. Regarding video content, it appears that students favour feedback on language, the micro-level rather than that on the content and structure of the writing. Although in second language acquisition, feedback on language has been an arguable topic when answering the question whether it leads to language development, it has a crucial role in scaffolding learners to notice the discrepancy between their work and the target language form (Sauro, 2009). The attention students give to language in 
writing can be seen in Alvira's study (2016), where the screencast feedback on writing was primarily on content, while language feedback at micro-level was also provided. However, the grammar aspect was the most mentioned by students in their evaluation on screencast feedback and they had shown significant progress. A study conducted by Chen et al. (2016) on written corrective feedback to EFL learners also shows that extended comments on the grammar of their writing is one of the students' strong preferences. In the current study, as adult language degree learners, understandably students emphasized more on language accuracy, especially when their proficiency level is not high enough to enable them to produce highly accurate work and complex content. Their writings are mostly narrative and descriptive. The need for language accuracy of those students also aligns with the primary purpose of the given written assignments, writing-to-learn language which can be reflected on the marking criteria used, in which language aspects count for $70 \%$ whilst content, ideas and structure are $30 \%$.

In this study, not every student was able to or willing to self-regulate errors, and those who were confident and did so, still needed to seek for reassurance. Putting aside their language competence, when students are adventurous and use some unlearnt language, the errors are very often beyond self-treatment. When at YA, students could not negotiate their own corrections with the marker as easily as they could do in a face-to-face teaching setting. Together with the students' need to understand the reason behind such corrections, both clear corrections (in script) and explanations (in video) become extremely important, to avoid students becoming 'lost in translation'. Therefore, it is not surprising that students would like the language feedback to be as detailed as possible, in other words comprehensive written corrective feedback. However, regardless of the student's preference, how effective the comprehensive WCF is in students' language improvement in this context is unknown.

\section{Screencast feedback doesn't necessarily lead to feedback engagement}

Several studies found that with screencast feedback, students tended to view feedback multiple times (Mahoney, et al., 2019), but it is unclear how students watched them, either repeating the whole video or stopping at certain points and restarting it next time, which is an unanswered question in the current study as well. Orlando (2016, p. 160) notes "instructors found that students were genuinely excited to receive the feedback in screencasting form". However, in this study, none of the students expressed 'excitement' when evaluating screencast feedback. Despite student's positive perceptions on video feedback, this study discovered that the existence of video feedback did not necessarily lead to learners actively engaging with such feedback. 
First, not all the learners watched their feedback videos, and some did not watch any of them. Inevitably, individual differences in skills, such as self-regulation, confidence and academic self-concept may have influenced learners' proactive recipience of feedback (Winstone et al., 2017) in addition to personal learning method preference. In general, those who were more actively engaged in the classroom teaching in the previous year tended to watch most of their feedback videos and/or watch multiple times (The marker was their module teacher in the year before YA). It seems that when students are self-motived autonomous learners, they are more likely to take feedback. At the same time, one issue that cannot be ruled out is the HE culture in which marks are very often used to indicate a student's performance or progression, which was cited by students in this study, even when the purpose of writing assignments was to provide an opportunity to practice the language rather than earning academic credit. In this study, this misconception was then exacerbated by the design of the online submission system, in which actual marks were the first thing that students saw when collecting the feedback. Although it is not clear whether those students read their marked scripts instead of watching video feedback, their ignorance of screencast feedback has, to some extent, implied their lack of feedback literacy and their lack of appreciation of feedback. There were no detailed explanations on their marked scripts, and sometimes it was deliberately left out with error indication only, so only reading marked scripts will not help them to fully understand correct forms.

Second, it is surprising to discover that in contradiction to their positive evaluation on screencast feedback, some students did not watch all their own feedback videos. This could be because of cognitive overload when watching two or three videos in one go and/or the amount of information covered in each video was overwhelming, as mentioned by a couple of students in this study. In this case, in addition to making students aware of their cognitive capacity, such as not watching all videos together and using the pause button, the scope of WCF might need to be reconsidered. Online records of video view numbers showed there was a slight tendency for students to watch more feedback videos on the term one assignment than those in term two. Two students who watched all their feedback videos in term one did not watch any given on their term two assignment. Reasons for this remain unknown, but one assumption is that they watched feedback on the term one assignment to make improvements on the term two assignment. After completing the term two assignment, they had less need to take feedback anymore. Zimbardi et al. (2017, cited in Carless \& Winstone 2020, p. 4) pointed out that "when assessment tasks are designed to build on earlier ones, and the links in a sequence are made explicit, students are more likely to use feedback". While such an assumption needs further proof, an intervention is needed, for example improving assignment design to create more opportunities for knowledge seeking and application by students, hence increasing feedback engagement, even when 
the feedback is in video format. In other words, learners must have an active role in feedback.

\section{Teachers' concern}

The study shows the learners' inclination towards screencast feedback and their desire to have detailed written corrective feedback. However, the major concern from teachers is that the process could be/is technically time-consuming, despite recognizing the pedagogical value of this practice, one that is appreciated by students. On the one hand, they believe video feedback is potentially more efficient than written feedback, as more information could be given which could reduce further clarification time. On the other hand, they worry too much time will be involved in the whole process, namely printing out the students' script which is in PDF file, correcting or indicating errors on the script, scanning it into a digital file, uploading on computer and then creating the video. The conventional feedback on paper seems to be more straightforward, even when as much detailed feedback as possible is given. More time might be needed to re-record or edit the video if the teacher was dissatisfied with the quality. Furthermore, inevitably, more detailed oral feedback requires more time input. Due to the fear of the process being timeconsuming, teachers were very cautious about how screencast feedback is used: not to apply to a big cohort individually, but to provide group feedback instead. However, several studies (Mahoney et al., 2019) suggest that markers find that the time required to produce video feedback is no more than that required for written feedback, or even less in some cases and, in other studies, video is considered to be a time-efficient way to provide feedback (Ice et al., 2007; Séror, 2012).

In this study, teachers commonly believe that feedback should be given as much as possible and they had paid more attention to the micro-level issues in feedback. Lee (2019) argues that when given written feedback, focused written corrective feedback is more beneficial to both the teachers and students than comprehensive written corrective feedback; that teachers could save time and students would have more room to take risks and build confidence. In the context where there are numerous errors, it could be challenging for teachers to make decisions on what to focus on and what to ignore, at least momentarily (Alvira, 2016). One possible solution is to establish early communication before teachers mark students' work to enable teachers to understand students, balance students' expectations and the workload and carefully plan feedback with pedagogical practice. It is worth mentioning Bond and Molloy's review (2013a, cited in Carless and Winstone, 2020, p. 7) that "it is impossible to justify the time spent crafting feedback messages if it does not have a positive impact on what students can do, so making feedback satisfying for teachers is as important as making it worthwhile for students." Although this early contact might again, from the teacher's point of view, require more time input, it will further help with personalizing the feedback and 
encourage student engagement. "Feedback information needs to be thoughtfully directed at the appropriate level if it is to be expected that it will be acted upon" (Bond and Molly, 2013b, p. 204). Moreover, teachers should have "the attitudes and will-power to overcome challenges and strive to develop productive feedback processes for students" (Carless and Winstone 2020, p. 4).

\section{Conclusion}

The study has investigated a group of Mandarin students' perceptions of screencast feedback on their academic work while on year abroad, as well as language teachers' views on such feedback. It concludes that the affordance offered by screencast feedback make screencast technology a good vehicle to deliver feedback to YA students, in that it is easy to receive, gives in-depth explanation and provides emotional support. In addition, the reading out loud by the native marker in videos particularly benefits Mandarin learners. The content of the video that focuses on comprehensive written corrective feedback was valued by those students, due to their low language proficiency level. However, the existence of such screencast feedback does not necessarily lead to student proactive feedback engagement. The study shows teachers understand the pedagogical benefits of screencast feedback but are concerned that the technical process is time consuming in relation to keeping the scope of feedback in their established practice. The implication of the current study is that although screencast can enhance students feedback experience, the role pedagogy plays cannot be underestimated in students feedback engagement. In this context, two aspects should be reconsidered: assignment design which should create an environment for students to act upon and implement feedback, and the scope of feedback, in particular written corrective feedback in foreign language writing which should be negotiated between teachers and students. It is necessary for both students and teachers to further develop feedback literacy to make the feedback process more efficient and effective, as teachers and students have a shared responsibility in this process (Carless and Winstone, 2020).

\section{Limitation}

One major limitation of this study is that the interviewer is the marker of the students' work. It is difficult to tell, to what extent students interview data is objective and neutral. This could possibly shed some light on the question why they gave positive evaluation on video feedback but did not watch all the personalized video feedback, in addition to other individual factors. Another limitation is the scale of this study due to the small number of research targets, thus the findings might not be generalized. 


\section{Recommendations for future research}

Some questions emerged from this study which are worth further investigation. First, what was the perception on feedback of those students who did not use screencast feedback? To understand their individual variables will help teachers to determine how best to mitigate their issues and personalize feedback in order to engage them. Second, how do students watch screencast videos, such as where do they pause the video, which sections do they watch more times etc.? With detailed analytical data, together with students' self-report, teachers will have a better understanding of students receiving written corrective feedback, which will further help teachers to manage the scope of written corrective feedback. Moreover, how do teachers effectively use screencast technology to enhance student feedback experience with the institution's support, on both technology deployment and further pedagogical understanding? Convincing findings will assist teachers to adjust their current practice to better support student learning.

\section{References}

Alharbi, W. (2017). E-Feedback as a Scaffolding Teaching Strategy in the Online Language Classroom, Journal of Educational Technology Systems, 46(2), 239-251, https://dor.org/10.1177/ 0047239517697966

ALVIRA, R. (2016). The Impact of Oral and Written Feedback on EFL Writers with the Use of Screencasts, PROFILE issues in teachers' professional development, 18 (2), 79-92. https://doi.org/10.15446/ profile.v18n2.53397

Bond, D., \& Molloy, E. (2013a). What is the Problem with Feedback? In Bond, D. \& Molly, E. (Eds.). Feedback in Higher and Professional Education: Understanding It and Doing It Well (pp. 1-10). London: Routledge.

Bond, D. \& Molly, E. (2013b). Decision-making for feedback. In Bond, D. \& Molly, E. (Eds.). Feedback in Higher and Professional Education: Understanding It and Doing It Well (pp. 202-218). London: Routledge.

Carless, D. \& Winstone, N. (2020). Teacher feedback literacy and its interplay with student feedback literacy, Teaching in Higher Education, 1-14. https://doi.org/10.1080/13562517.2020.1782372

Chen, S., NAssAJI, H. \& LIU, Q. (2016). EFL learners' perceptions and preferences of written corrective feedback: a case study of university students from Mainland China, Asian-Pacific journal of second and foreign language education, 1 (5), 1-17. https://doi.org//10.1186/s40862-016-0010-y

HARPER, F., GREEN, H. \& FERnANDEZ-Toro, M. (2018). Using screencasts in the teaching of modern languages: investigating the use of Jing® in feedback on written assignments, Language learning journal, 46 (3), 277-292. https://doi-org.libezproxy.open.ac.uk/10.1080/09571736.2015.1061586

ICE, P., CURTIS, R., Phillips, P., \& WELlS, J. (2007). Using asynchronous audio feedback to enhance teaching presence and student sense of community. Journal of Asynchronous Learning Networks, 11(2), 3-25.

ICE, P., Swan, K., Diaz, S., Kupczynski, L. \& Swan-Dagen, A. (2010). An Analysis of Students' Perceptions of the Value and Efficacy of Instructors' Auditory and Text-Based Feedback Modalities across Multiple Conceptual Levels, Journal of educational computing research, 43 (1), 113-134. https:// doi.org/10.2190/EC.43.1.g

LEE, I. (2019). Teacher written corrective feedback: Less is more. Language Teaching, 52(4), 524-536. https://doi.org/doi:10.1017/S0261444819000247

Mahoney, P., Macfarlane, S. \& AJJAWI, R. (2019). A qualitative synthesis of video feedback in higher education, Teaching in Higher Education, 24 (2), 157-179, https://doi.org/10.1080/ 13562517.2018.1471457 
MANCHóN, R. M. (2011). Situating the learning-to-write and writing-to-learn dimensions of L2 writing. In MANCHón, R. M. (Ed.). Learning-to-Write and Writing-to-Learn in an Additional Language (pp. 3-17). John Benjamins Publishing Company.

MAO, Z \& LEE, I. (2020). Feedback scope in written corrective feedback: Analysis of empirical research in L2 contexts, Assessing writing, 45, 100469. https://doi.org/10.1016/j.asw.2020.100469

MCGARRELL, H., \& VERBEEM, J. (2007). Motivating revision of drafts through formative feedback. ELT Journal, 61(3), 228-236. https://doi.org/10.1093/elt/ccm030

OrLando, J. (2016). A Comparison of Text, Voice, and Screencasting Feedback to Online Students, American Journal of Distance Education, 30(3), 156-166, https://doi.org/10.1080/ 08923647.2016.1187472

ORTEGA, L. (2011). Reflections on the learning-to-write and writing-to-learn dimensions of second language writing. In MANCHóN, R. M. (Ed.). Learning-to-Write and Writing-to-Learn in an Additional Language (pp. 3-17). John Benjamins Publishing Company.

SAURo, S. (2009). Computer-mediated corrective feedback and the development of L2 grammar, Language Learning \& Technology, 13 (1), 96-120. http://llt.msu.edu/vol13num1/sauro.pdf

SÉRoR, J. (2012). Show me! Enhanced feedback through screencasting technology, TESL Canada Journal, 30(1), 104-116.

Stern, L. A., \& Solomon, A. (2006). Effective faculty feedback: The road less traveled. Assessing Writing, 11(1), 22-41. https://doi.org/10.1016/j.asw.2005.12.001

Thomas, R., West, R., \& Borup, J. (2017). An Analysis of Instructor Social Presence in Online Text and Asynchronous Video Feedback Comments. The Internet and Higher Education, 33, 61-73. https:// doi.org/10.1016/j.iheduc.2017.01.003

Thompson, R., \& LEE, M. J. (2012). Talking with Students through Screencasting: Experimentations with Video Feedback to Improve Student Learning. The Journal of Interactive Technology and Pedagogy. 1(1) Retrieved from https://jitp.commons.gc.cuny.edu/talking-with-students-throughscreencasting-experimentations-with-video-feedback-to-improve-student-learning/

Vincelette, E. J., \& Bostic, T. (2013). Show and Tell: Student and Instructor Perceptions of Screencast Assessment. Assessing Writing, 18, 257-277. er Ltd. All rights reserved. http://dx.doi.org/10.1016/ j.asw.2013.08.001

Winstone, N. E., Nash, R. A., Parker, M. \& Rowntree, J. (2017) Supporting Learners' Agentic Engagement With Feedback: A Systematic Review and a Taxonomy of Recipience Processes, Educational Psychologist, 52:1, 17-37, https://doi.org/10.1080/00461520.2016.1207538

Zimbardi, K., Colthorpe, K., Dekker, A., Engstrom, C., Bugarcic, A., Worthy, P., Victor, R., Chunduri, P., LLuKA, L. \& LoNG, P. (2017). Are They Using My Feedback? The Extent of Students' Feedback Use has a Large Impact on Subsequent Academic Performance. Assessment and Evaluation in Higher Education 42 (4): 625-664. https://doi.org/10.1080/02602938.2016.1174187

\section{Author}

Zhiqiong Chen (Mrs), Warwick University, e-mail: zhiqiong.chen@wawick.ac.uk

Zhiqiong Chen is a senior teaching fellow of Chinese at the School of Modern Language and Cultures of Warwick University. Over the past 15 years, she has been teaching various academic and lifelong learning Mandarin modules. Outside Warwick University, she also delivered the online Mandarin course for the Open University as an associate lecturer between 2009 to 2020. Since then, she has taken a consultant role at the Open University, co-authoring online Mandarin courses, and providing language advice to online Mandarin learners. Her research interests are in language teaching methodology, blended learning and student engagement. 